\title{
Interdisciplinarity and Internationalization: Two Challenging Aspects of Nursing Research
}

\section{Denize Cristina de Oliveira ${ }^{1}$}

The establishment of an interdisciplinary field in Nursing inter-relates to the process of internationalization, as the specificity of the knowledge produced is directly related to the field in which it is part, determining the loci of publication and possible partners both within Brazil and abroad.

It is understood that an interdisciplinary field is the articulation of different disciplines having the study objective in common, which in the case of nursing is defined as nursing care and health. It is recognized that disciplinary aspect identification of a field of knowledge is an essential condition for interdisciplinary implementation, maintaining the field's proper/own identity ${ }^{(1)}$.

Nursing has interfaces with numerous other areas in the production of knowledge, involving Biological and Health Sciences (Medicine, Biology, Nutrition, Physical Therapy, and others), the Humanities (Psychology, Education, History) and Applied Social Sciences (Organizations, Work, Education, Communication, Information Technology and Economics). Many of these interfaces/interactions are already recognized research fields and incorporated tradition, such as the Nursing in the Collective Health sector that establishes important dialogue/discourse with the Public Health, Collective Health , Epidemiology, Anthropology and Economic sectors, among others.

Currently, Post-Graduate Nursing Programs (PGPS) involve diverse disciplinary arrangements in relation to their target audience - incorporating doctors, physiotherapists, nutritionists and other health professionals, and to the subject matters - clinical health care, health sciences, nursing and biosciences, family health, and teacher training for the NHS (National Health System). This distinctive feature can be observed in the large volume of publications in journals from other areas and also by the end user, as the Nursing books and articles are cited by researchers from different fields of knowledge.

International integration of Nursing is mainly done through PGPs and can be observed by various indicators, including the degree of internationalization. In 2013, 57 Nursing PGPs were evaluated noting that $28.05 \%$ are consolidated with compatible performance grades/scores of 5, 6 and 7, and $19.29 \%$ had recognized national leadership with a score of 5 and only $8.76 \%$ had their excellence and international integration recognized by scores of 6 and 7 . In terms of growth, there has been gradual and progressive upward shift of the PGP qualification, well-matched to its development history in Brazil. The distinctive trait of this area is that the post-graduate courses in nursing were, until a few years ago, only located in a small number of countries, as this level of training is just a recent reality in countries of Europe, Asia, Oceania and Africa. In this scenario, Brazil is one of the countries in which the development of scientific research has progressed over a longer time, having accumulated critical mass knowledge and recollection that sustains its scientific production and PGPs to this day.

Internationalization can also be observed in consolidated partnerships with research centers abroad in transdisciplinary dialogue/exchanges for nursing and other fields of knowledge, for example the Maison des Sciences de L'Homme - FRA, Université Sorbonne - FRA, University of Lisbon - POR, University of Alberta - CAN, University of McGill - CAN, King's College London - UK, Linköping University - SWE, Universidad Autónoma del Estado de Mexico - MEX, University of Washington - USA, University of California San Francisco - USA, among others ${ }^{(2-4)}$. We emphasize that those partnerships build a path of hybrid knowledge provided by the exchanges between different scientific fields, as they merge mixed concepts and methods of doing science with scientific and technological culture among the relevant factors in doing science.

International scientific production can be seen in the number of documents indexed in the Scopus database / SCImago and consequently in the world rankings in which Brazilian Nursing ranked 26th in production of the area in 2000, rising up to 6th place in 2012, surpassed only by the United States, the UK, Australia, Canada and France. By analyzing the citations made in the same year, Brazil reaches 18th place in total number of citations, 21st position in/ for the $\mathrm{H}$ index and the 9th position in self-citation, making for an average of 3.33 citations per paper, the lowest of all the health fields in Brazil(5).

It is considered that the indicators used in evaluating internationalization processes of researchers and PGPs have expressive inductive power of actions and the modus operandi of the area, even if they require the combination of a set of indicators. The discussion about these indicators is a task for all of us.

It is suggested/recommended to follow some criteria that could give greater visibility and discriminatory power to evaluation: participation in research projects involving research groups from foreign institutions; exchange of students and professors involving reciprocal financing; publications in journals of international circulation and with high impact on the intellectual output of the program (Qualis A1 and A2); participation in editorial committees and editorials published

\footnotetext{
${ }^{1}$ Tenured Professor, the Faculty of Nursing, Rio de Janeiro State University, Rio de Janeiro, RJ, Brazil. E-mail: dcouerj@gmail.com
} 
in journals of international circulation; granting resources and funding for research in international scientific agencies; offering courses in other countries; attracting students from abroad for post-doctorate programs; awarding dual degrees from PGPs abroad ; participation of professors in organizing international scientific events, conferences and roundtable/ sharing-of-best-practices discussions; participation on international scientific association boards and in international awards $^{(2,6)}$. Currently, the PGP area with scores of 6 and 7 and also some with 5 tackle /attend to/deal with/handle some of these issues but not all of them, establishing a divide/division in relation to other programs.

However, the essential question for which we still lack consensus is this: Who should we want to develop our international partnerships with and what degree of interdisciplinarity can be supported by the area without it losing its identity? This is a question that deserves to be better debated. We believe it is necessary to consider the process of internationalization along with what interdisciplinarity we want (or how much of it we want) for the establishment of nursing research, as the partnerships established abroad can boost/enhance our science for different possible identities.

\section{References}

1. Oliveira DC, Ramos FRS, Barros ALBL, Nóbrega MML. Classificação das áreas de conhecimento do CNPq e o campo da Enfermagem: possibilidades e limites. Rev Bras Enferm. 2013;66(n.esp):60-5.

2. Oliveira DC. Formation pour la recherche et la construction des sciences infirmières au Brésil. In: Jouet $\mathrm{E}$, Las Vergnas O, Noël-Hureaux E, organizadores. Nouvelles coopérations réflexives en santé: de l'expérience des malades et des professionnels aux partenariats de soins, de formation et de recherche. Paris: Editions des Archives Contemporaines; 2014. p. 120-38.

3. Scochi CGS, Munari DB, Gelbcke FL, Erdmann AL, Rivero de Gutiérrez MG, Rodrigues RAP. Pós-graduação Stricto Sensu em Enfermagem no Brasil: avanços e perspectivas. Rev Bras Enferm. 2013;66(n.esp):80-9.

4. Erdmann AL. Challenges to nursing in CAPES: highly qualified products. Rev Esc Enferm USP. 2008;42(2):216-7.

5. SCImago Journal \& Country Rank - SJR [Internet]. [cited 2014 June 11]. Available from: http://www. scimagojr.com/

6. Ketefian S. Doctoral education in the context of international development strategies. Int J Nurs Stud [Internet]. 2008 [cited 2014 June 11];45(10):1401-2. Available from: http://www.sciencedirect.com/ science/article/pii/S0020748908000333 